\title{
Internet: aliada ou vilã no ensino aprendizagem de eletromagnetismo?
}

\author{
Elexlhane Guimarães Damasceno de Siqueira ${ }^{1}$ Daniela Fontana Almenara ${ }^{2}$, Gleisivani Rodrigues \\ Saldanha ${ }^{3}$, Jacinta Santos Silva ${ }^{4}$, Queila da Silva Ferreira ${ }^{5}$ \\ 1, 2, 3, 4, 5 Universidade Federal de Rondônia (UNIR)
}

Palavras-Chave: Eletromagnetismo, experimentos, internet.

\section{Introdução}

Os estudantes são naturalmente curiosos, utilizam diversas tecnologias em seu dia a dia e as aulas tradicionais não têm sido capazes de despertar o desejo em aprender. Em vista disso, aliar experimentação a tecnologias propicia a realização de atividades que desenvolvem a potencialidade do protagonismo juvenil e aprimoram o conhecimento, tornando o ensino realmente significativo.

Atualmente os professores têm recorrido bastante a experimentos com materiais acessíveis. De acordo com Araújo e Abib (2003, p. 186) "uma modalidade de uso da experimentação que pode despertar facilmente o interesse dos estudantes relaciona-se à ilustração e análise de fenômenos básicos presentes em situações típicas do cotidiano" onde a partir da interação do indivíduo com a realidade do mundo que os cerca pode aumentar o interesse dos estudantes em sala de aula. No entanto, fora do ambiente escolar é necessário continuar mantendo esse interesse, a internet tem sido uma ótima aliada para fins de estudo, o que garante uma melhora no ensino-aprendizagem de física. Mas, se não houver uma orientação que aborde sobre os riscos de navegação nas redes, a internet pode tornar-se vilã, caso essa busca seja em websites não confiáveis.

No âmbito da teoria de Ausubel (Moreira, 2006), recomenda o desenvolvimento de conceitos subsunçores que facilitem a aprendizagem subsequente. Nesse contexto, este trabalho busca inovar no ensino e aprendizagem em física, abordando temas de eletromagnetismo com metodologias diferenciadas, onde o estudante participa mais ativamente da construção do próprio conhecimento, não somente em sala de aula, mas também fora dela por meio de mídias audiovisuais.

A ferramenta tecnológica empregada como produto educacional foi um website, contendo roteiros de aulas prontos para uso de docentes e discentes, sendo que o professor poderá baixá-lo e adaptar a sua realidade escolar e cultural. Tal ferramenta permite acesso à atividades a serem desenvolvidas em sala, além de artigos científicos, vídeos e experimentos criados pela autora e também os obtidos de fontes seguras e previamente analisados.

\section{Metodologia e Material}

A metodologia consistiu em várias etapas. Primeiramente, a escolha de se utilizar a internet como ferramenta para auxiliar o estudo do eletromagnetismo se deu porque os estudantes anseiam por metodologias que instiguem a curiosidade e proporcionem interação, já que estão habituados a utilizarem as tecnologias em seu cotidiano. Em seguida passou-se a construção de roteiros de aula e experimentos, entre eles eletroímãs em campainha magnética, experiência de Oersted, motor de Faraday e corrente induzida, separados como propostas de aulas semanais, as quais ficaram disponíveis no endereço elexeletromagnetismo.wordpress.com. Neste website é possível obter previamente toda a teoria e prática necessárias ao entendimento do eletromagnetismo utilizado nas aulas, onde possui além das atividades para os alunos, também o passo-a-passo para o professor de como implementar toda essa metodologia em sala de aula.

Os estudantes participaram de uma palestra cujo objetivo era conscientizar sobre a importância de usar as mídias para aprendizagem. Em seguida, a turma selecionada para aplicação da pesquisa, inserida no terceiro ano do Ensino Médio, respondeu a um questionário sobre os conceitos que seriam ministrados durante toda a execução do projeto. Em sala, os alunos tiveram aulas teóricas que eram intercaladas com experimentos apresentados pelo docente e pelos discentes. Todas as sequências didáticas ficaram disponibilizadas no site, possibilitando rever o 
conteúdo trabalhado e acessar os vídeos com experimentos, o que propicia uma consolidação dos conhecimentos adquiridos.

\section{Resultados e Discussão}

Com a escolha da utilização de um website para desenvolvimento do tema eletromagnetismo relacionado aos conceitos de indução, campo e força magnética, viu-se a necessidade de averiguar se os discentes realizavam a navegação e uso da internet com responsabilidade, para isso a palestra sobre a aprendizagem na rede constatou que embora os estudantes saibam lidar com aparatos tecnológicos, não utilizam websites confiáveis no processo de aquisição do conhecimento cientifico e em sua maioria empregam a tecnologia apenas para ampliar seu convívio em redes sociais, jogos, visualização de filmes dentre outros entretenimentos.

Verificou-se que os estudantes tinham pouco conhecimento prévio sobre os conceitos apresentados, e nesse contexto o website foi de grande valia, consolidando os conhecimentos adquiridos e possibilitando o aprofundamento nos conteúdos abordados em sala ao acessarem roteiro de aulas e experimentos por meio deste ambiente virtual.

Em seguida, o docente apresentou os conceitos sobre o eletromagnetismo intercalando-os com a realização de experimentos em sala de aula. Essas experiências construídas com base nos roteiros disponíveis no website, oportunizou aos estudantes a interação com os conteúdos estudados, sendo que a sequência disponível sempre ancorava os próximos conceitos, e despertou neles a curiosidade para o aprofundamento do conhecimento cientifico. Dessa forma observou-se através de uma verificação de aprendizagem bimestral que os estudantes demonstraram um maior domínio nos conceitos trabalhados, os quais no momento do preenchimento do questionário prévio não haviam sido manifestados.

\section{Conclusões}

A disponibilização de um website para auxiliar os docentes a direcionarem os estudantes no ensino aprendizagem de alguns tópicos de eletromagnetismo contendo roteiros de aulas e experimentos, bem como materiais de pesquisa selecionados como artigos e vídeos confiáveis, demonstrou ser de grande valia por permitir ao aluno complementar e retomar os conceitos estudados em sala quando considerar necessário.

A metodologia de se utilizar o website para o ensino do eletromagnetismo promoveu indícios de uma aprendizagem significativa, onde o estudante demonstrou ter construído um conhecimento embasado cientificamente e contextualizado, proporcionando uma integração entre teoria e prática e permitindo uma aprendizagem significativa.

\section{Agradecimentos}

À Capes pela bolsa de estudos, ao governo do estado de Rondônia e a equipe gestora da E.E.E.F.M. Nilson Silva pelo apoio. Aos alunos do 3ํao da escola E.E.E.F.M. Nilson Silva por participarem do projeto.

\section{Referências}

ARAUJO, M. S. T. de; ABIB, M. L. V. dos S. Atividades Experimentais no Ensino de Física: Diferentes Enfoques, Diferentes Finalidades. Revista Brasileira de Ensino de Física, vol. 25, n. 2, p. $184-189,2003$.

MOREIRA, M. A.; MASINI, E. F. S. Aprendizagem Significativa: a teoria de David Ausubel. São Paulo: Centauro, 2006. 